\title{
Jeotgalicoccus pinnipedialis sp. nov., from a southern elephant seal (Mirounga leonina)
}

\author{
Correspondence \\ Matthew D. Collins \\ M.D.Collins@reading.ac.uk
}

\section{Lesley Hoyles, ${ }^{1}$ Matthew D. Collins, ${ }^{1}$ Geoffrey Foster, ${ }^{2}$ Enevold Falsen ${ }^{3}$ and Peter Schumann ${ }^{4}$}

${ }^{1}$ School of Food Biosciences, University of Reading, Reading, UK

2SAC Veterinary Services, Inverness, UK

${ }^{3}$ CCUG, Culture Collection of the University of Göteborg, Department of Clinical Bacteriology, University of Göteborg, Sweden

${ }^{4} \mathrm{DSMZ}$ - Deutsche Sammlung von Mikroorganismen und Zellkulturen GmbH, Braunschweig, Germany

\begin{abstract}
A previously unknown Gram-positive, catalase-positive, facultatively anaerobic, non-spore-forming, coccus-shaped bacterium (A/G14/99/10 $)$, originating from the mouth of a female southern elephant seal, was subjected to a taxonomic analysis. Comparative $16 \mathrm{~S}$ rRNA gene-sequencing showed that the organism formed a hitherto unknown subline within the catalase-positive, low-G $+C$, Gram-positive cocci, exhibiting a specific association with species of the genus Jeotgalicoccus. Sequence divergence values of approximately $7 \%$, together with phenotypic differences, showed the unknown bacterium to be distinct from the two described species of this genus, Jeotgalicoccus halotolerans and Jeotgalicoccus psychrophilus. Based on phenotypic and phylogenetic considerations, it is proposed that strain $A / G 14 / 99 / 10^{\top}=$ CCUG $42722^{\top}=$ CIP $107946^{\top}$ from the mouth of a seal be classified as the type strain of a novel species of the genus Jeotgalicoccus, Jeotgalicoccus pinnipedialis sp. nov.
\end{abstract}

The genus Jeotgalicoccus was proposed by Yoon et al. (2003) to accommodate some Gram-positive, non-motile, catalaseand oxidase-positive, coccus-shaped organisms isolated from jeotgal, a traditional Korean fermented seafood. Two species of the genus, Jeotgalicoccus halotolerans and Jeotgalicoccus psychrophilus, are currently recognized. The genus Jeotgalicoccus forms a phylogenetically distinct line of descent that is close to, but separate from, members of the genus Salinicoccus and other catalase-positive, coccusshaped genera (Yoon et al., 2003). During the course of a study of taxonomically problematic organisms isolated from seals, we have characterized a Jeotgalicoccus-like organism from the oral cavity of a southern elephant seal. Based on the results of a polyphasic taxonomic study, it is clear that this coccus-shaped organism represents a novel species of the genus Jeotgalicoccus, for which we propose the name Jeotgalicoccus pinnipedialis.

Strain A/G14/99/10 ${ }^{\mathrm{T}}$ was isolated from a mouth swab taken from a female southern elephant seal as part of a British Antarctic Survey study in the South Orkneys, in 1993. The strain was grown aerobically at $37^{\circ} \mathrm{C}$ on Columbia agar (Oxoid) supplemented with $5 \%$ sheep blood. It was

The GenBank EMBL/DDBJ accession number for the 16S rRNA gene sequence of Jeotgalicoccus pinnipedialis A/G14/99/10 ${ }^{\top}$ is AJ251530. characterized biochemically using the API STAPH, API ID32STAPH, API CORYNE and API ZYM systems according to the manufacturer's instructions (bioMérieux). For cellular fatty acid determination, the organism was grown on sheep blood agar at $37^{\circ} \mathrm{C}$ for 3 days, and methyl esters were analysed using the MIDI microbial identification system. The G + C content of the DNA of strain A/G14/99/ $10^{\mathrm{T}}$ was determined by HPLC according to Mesbah et al. (1989). Isoprenoid quinones were extracted as described by Collins et al. (1977) and analysed by HPLC as described by Groth et al. (1997). Polar lipids were extracted by the method of Minnikin et al. (1979) and analysed by twodimensional TLC and by spraying with specific reagents (Collins \& Jones, 1980). The 16S rRNA gene of the isolate was amplified by PCR and directly sequenced using a Taq dye-deoxy terminator cycle sequencing kit (Applied Biosystems) and an automated DNA sequencer (model 377, Applied Biosystems). The closest known relatives of the novel isolate were determined by performing database searches in the GenBank/EMBL data libraries. The determined sequence and those of its nearest phylogenetic relatives were aligned using the program CLUSTAL W (Thompson et al., 1994). The resulting multiple sequencealignment was corrected manually, and a distance matrix was calculated using the program DNADIST (using the Kimura 2-correction parameter) (Felsenstein, 1989). A 
phylogenetic tree was constructed using the neighbourjoining method with the program NEIGHBOR (Felsenstein, 1989). The stability of the groupings was estimated by bootstrap analysis (500 replications) using the programs SEQBOOT, DNADIST, NEIGHBOR and CONSENSE (Felsenstein, 1989).

Strain A/G14/99/10 ${ }^{\mathrm{T}}$ stained Gram-positive, and upon microscopic examination appeared as non-motile cocci (approximately $0 \cdot 7-1 \mu \mathrm{m}$ in diameter) arranged in a typical Staphylococcus aureus conformation (i.e. in 'bunches of grapes'), in pairs and in tetrads. Cells were non-acid fast and non-spore forming. The strain grew both aerobically and in an enriched- $\mathrm{CO}_{2}$ environment, and was catalaseand oxidase-positive. It also grew in 2 and $6 \% \mathrm{NaCl}$ but not in 0 or $14 \% \mathrm{NaCl}$. The organism failed to give any positive reactions with API STAPH. Using the API ID32STAPH system, weak activity for pyrrolidonyl arylamidase was detected; all other tests gave negative results with this system. Using the API ZYM system, activity was detected for acid phosphatase, phosphoamidase and ester lipase C8 (weak reaction); no other enzymes were detected with this system. Using the API CORYNE system, positive results were obtained for pyrrolidonyl arylamidase, pyrazinamidase and gelatin hydrolysis. The long-chain cellular fatty acids of the organism were found to be primarily of the iso- and anteiso-methyl branched-chain types. The major acids corresponded to anteiso- $\mathrm{C}_{15: 0}(60 \%)$ and iso- $\mathrm{C}_{15: 0}$ $(22.9 \%)$, with other acids [namely anteiso- $\mathrm{C}_{13: 0}(0 \cdot 8 \%)$, iso- $\mathrm{C}_{13: 0}(1 \%), \mathrm{C}_{14: 0}(1 \cdot 5 \%)$, iso- $\mathrm{C}_{14: 0}(1 \cdot 6 \%), \mathrm{C}_{16: 0}$ $(2 \cdot 2 \%)$, iso- $\mathrm{C}_{16: 0}(1 \cdot 6 \%)$, iso- $\mathrm{C}_{17: 0}(1 \cdot 9 \%)$, anteiso- $\mathrm{C}_{17: 0}$ $(4 \cdot 5 \%)$, iso- $\mathrm{C}_{18: 0}(0 \cdot 6 \%)$ and iso- $\left.\mathrm{C}_{19: 0}(0 \cdot 4 \%)\right]$ present in only minor amounts. The major respiratory quinone of strain A/G14/99/10 ${ }^{\mathrm{T}}$ was MK-7 (89\%), with MK-8 (3\%) and MK-6 (5\%) present in minor amounts. The polar lipids of the strain consisted of diphosphatidylglycerol, phosphatidylglycerol, phosphatidylinositol and an unidentified phospholipid. No aminolipids or glycolipids were detected. The $\mathrm{G}+\mathrm{C}$ content of the DNA of strain A/G14/99/10 ${ }^{\mathrm{T}}$ was $38.6 \mathrm{~mol} \%$. To ascertain the phylogenetic position of strain A/G14/99/10 ${ }^{\mathrm{T}}$, its almost complete $16 \mathrm{~S}$ rRNA gene sequence (1419 bp) was determined. Sequence database searches revealed the strain to be most closely related to species of the genera Jeotgalicoccus and Salinicoccus (approximately 7 and $9 \%$ sequence divergence, respectively), with species of other genera more distantly related (data not shown). A tree, constructed using the neighbourjoining method, depicting the phylogenetic relationships of strain A/G14/99/10 ${ }^{\mathrm{T}}$, is shown in Fig. 1. The strain formed a distinct subline within the low- $\mathrm{G}+\mathrm{C}$, Grampositive cocci, branching at the periphery of a cluster formed by J. halotolerans and J. psychrophilus. The association of strain A/G14/99/10 ${ }^{\mathrm{T}}$ with the genus Jeotgalicoccus was statistically highly significant (100\% bootstrap resampling value). Species of the genera Macrococcus and Salinicoccus were the next nearest relatives of the novel strain, but they formed quite separate and robust clusters (Fig. 1).

From the comparative 16S rRNA gene sequence analysis, it is evident that the unidentified, catalase-positive, coccusshaped organism represents a hitherto unknown taxon. Phylogenetically, strain A/G14/99/10 $0^{\mathrm{T}}$ displays a significant affinity with the genus Jeotgalicoccus. This association with Jeotgalicoccus is also consistent with phenotypic criteria, including chemical biomarkers. In particular, the longchain cellular fatty acid profile of strain A/G14/99/10 ${ }^{\mathrm{T}}$ is very similar to that reported (Yoon et al., 2003) for other Jeotgalicoccus species (i.e., primarily methyl branched-chain acids with anteiso- $\mathrm{C}_{15: 0}$ predominating). Fatty acid composition is known to be dependent on growth conditions, and the observed minor quantitative differences between species possibly reflect the different media and culture conditions employed in the present study. The menaquinones and polar lipids of the unknown bacterium also closely resembled those of J. halotolerans and J. psychrophilus (Yoon et al., 2003). By contrast, the absence of glycolipids and the synthesis of predominantly menaquinones with seven isoprene units serve to distinguish the seal bacterium from members of the genus Salinicoccus, which possess glycolipids and produce MK- 6 as the major menaquinone (Ventosa et al., 1990, 1992). The DNA G +C content of strain $\mathrm{A} / \mathrm{G} 14 / 99 / 10^{\mathrm{T}}(38.6 \mathrm{~mol} \%)$ is also significantly lower than that of Salinicoccus species (approximately

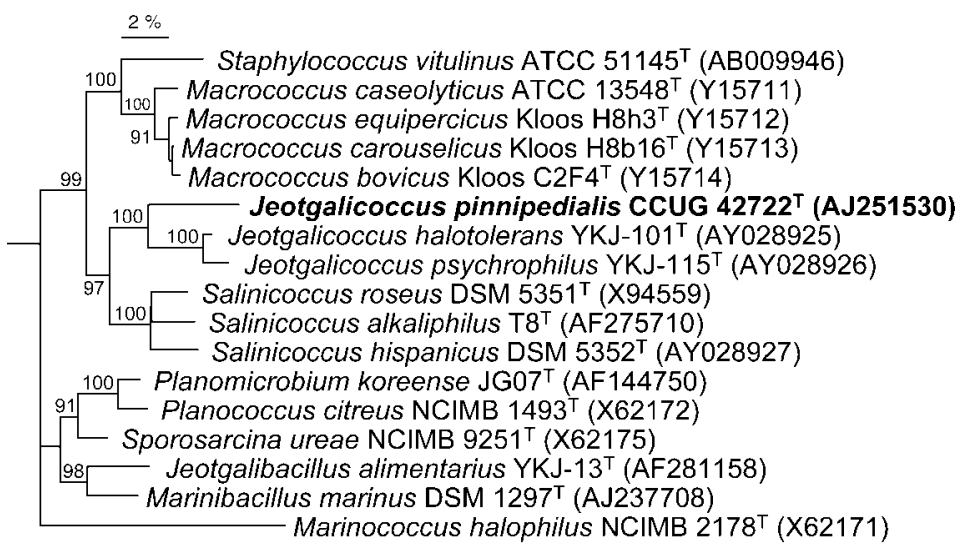

Fig. 1. Neighbour-joining tree showing the affiliation of Jeotgalicoccus pinnipedialis sp. nov. $A / G 14 / 99 / 10^{\top}$ with members of the genus Jeotgalicoccus. The tree was based on an analysis of approximately 1350 bases. Statistically significant bootstrap values are shown at the nodes and are expressed as a percentage of 500 replications. 
46-51 mol\%) (Ventosa et al., 1990, 1992), but is close to the value reported for Jeotgalicoccus species (42 mol\%) (Yoon et al., 2003). From $16 \mathrm{~S}$ rRNA gene-sequence divergence considerations $(7.5 \%$ from both $J$. psychrophilus and J. halotolerans, corresponding to 94 mismatches and 12 unmatched bases out of 1419), it is clear that strain A/G14/ $99 / 10^{\mathrm{T}}$ merits classification as a distinct species of the genus Jeotgalicoccus, forming a relatively deep branch within the genus. Overall, phenotypically, the strain closely resembles J. halotolerans and J. psychrophilus. However, unlike J. psychrophilus, strain A/G14/99/10 ${ }^{\mathrm{T}}$ can grow at 37 and $42{ }^{\circ} \mathrm{C}$. It further differs from $J$. psychrophilus by failing to grow in $14 \% \mathrm{NaCl}$ or at $4{ }^{\circ} \mathrm{C}$. Growth in $\mathrm{NaCl}$ also serves to distinguish strain $\mathrm{A} / \mathrm{G} 14 / 99 / 10^{\mathrm{T}}$ from J. halotolerans, since unlike $J$. halotolerans, the seal isolate does not grow in the absence of $\mathrm{NaCl}$ or in the presence of $20 \% \mathrm{NaCl}$ (Yoon et al., 2003). Therefore, on the basis of phenotypic and phylogenetic evidence, we consider strain A/G14/99/10 to merit classification as a novel species of the genus Jeotgalicoccus, for which we propose the name Jeotgalicoccus pinnipedialis sp. nov. Tests that are useful in distinguishing $J$. pinnipedialis from J. psychrophilus and J. halotolerans are shown in Table 1 .

\section{Description of Jeotgalicoccus pinnipedialis sp. nov.}

Jeotgalicoccus pinnipedialis (pin.ni.ped.i.a'lis. N.L. masc. adj. pinnipedialis pertaining to pinnipeds).

Cells stain Gram-positive and are coccus-shaped, appearing in 'bunches of grapes', in pairs or in tetrads. Cells are non-acid fast and non-motile. Colonies on blood agar are non-haemolytic, buff or fawn, round, convex and approximately $2 \mathrm{~mm}$ in diameter after $24 \mathrm{~h}$ aerobic incubation. Colonies have a similar appearance on nutrient agar. Growth is not enhanced by increased concentrations of $\mathrm{CO}_{2}$. Grows at 25 and $42{ }^{\circ} \mathrm{C}$, but not at $4{ }^{\circ} \mathrm{C}$. Growth occurs

Table 1. Differential phenotypic characteristics of J. pinnipedialis, J. halotolerans and J. psychrophilus

\begin{tabular}{|lccc|}
\hline Characteristic & $\begin{array}{c}\text { J. } \\
\text { pinnipedialis }\end{array}$ & $\begin{array}{c}\text { J. } \\
\text { halotolerans }\end{array}$ & $\begin{array}{c}\text { J. } \\
\text { psychrophilus }\end{array}$ \\
\hline Growth at: & & & \\
$4{ }^{\circ} \mathrm{C}$ & - & + & + \\
$37^{\circ} \mathrm{C}$ & + & + & - \\
$42^{\circ} \mathrm{C}$ & + & + & - \\
Growth in NaCl: & & + & + \\
$0 \%$ & - & + & - \\
$14 \%$ & - & + & - \\
$20 \%$ & - & & - \\
Acid production & from: & + & \\
Arabinose & - & + & \\
D-Mannitol & - & & \\
\end{tabular}

${ }^{\star}$ Data for reference species taken from Yoon et al. (2003). in 2 and $6 \% \mathrm{NaCl}$ but not in 0 or $14 \% \mathrm{NaCl}$. Catalase- and oxidase-positive. Using API systems, acid is not produced from arabinose, cellobiose, glucose, glycogen, fructose, lactose, mannose, mannitol, maltose, melibiose, $\alpha$-methyl D-glucoside (methyl $\alpha$-D-glucopyranoside), raffinose, ribose, sucrose, trehalose, turanose, xylitol or D-xylose. Gelatin is hydrolysed, but aesculin and hippurate are not. Activity for acid phosphatase, phosphoamidase, pyrazinaminidase and pyrrolidonyl arylamidase is detected. Activity for ester lipase C8 is either weak or absent. No activity is observed for alkaline phosphatase, arginine dihydrolase, arginine arylamidase, chymotrypsin, cystine arylamidase, esterase C4, $\alpha$-fucosidase, $\alpha$-galactosidase, $\beta$-galactosidase, $\alpha$-glucosidase, $\beta$-glucosidase, $\beta$-glucuronidase, leucine arylamidase, lipase C14, $\alpha$-mannosidase, ornithine decarboxylase, $\mathrm{N}$-acetylglucosaminidase, trypsin, valine arylamidase or urease. Acetoin is not produced. Nitrate is not reduced to nitrite. The long-chain cellular fatty acids are primarily of the anteiso- and iso-methyl branched types, with anteiso$\mathrm{C}_{15: 0}$ and iso- $\mathrm{C}_{15: 0}$ predominating. Unsaturated menaquinones with 7 isoprene units (MK-7) are the predominant respiratory lipoquinones. The polar lipids consist of diphosphatidylglycerol, phosphatidylglycerol, phosphatidylinositol and an unidentified phospholipid.

The type strain is $\mathrm{A} / \mathrm{G} 14 / 99 / 10^{\mathrm{T}} \quad\left(=\mathrm{CCUG} 42722^{\mathrm{T}}=\right.$ $\left.\mathrm{CIP} 107946^{\mathrm{T}}\right)$. The $\mathrm{G}+\mathrm{C}$ content of its DNA is $38.6 \mathrm{~mol} \%$. Isolated from a mouth swab taken from a southern elephant seal. Habitat is not known.

\section{Acknowledgements}

We are grateful to Lesley Thomson (Royal Devon \& Exeter Hospitals NHS Trust), formerly British Antarctic Survey, Plymouth (UK) for providing biological samples. The Scottish Stranding Scheme receives support from the UK Department of Environment, Farming and Rural Affairs.

\section{References}

Collins, M. D. \& Jones, D. (1980). Lipids in the classification and identification of coryneform bacteria containing peptidoglycans based on 2,4-diaminobutyric acid. J Appl Bacteriol 48, 459-470.

Collins, M. D., Pirouz, T., Goodfellow, M. \& Minnikin, D. E. (1977). Distribution of menaquinones in actinomycetes and coryneform bacteria. J Gen Microbiol 100, 221-230.

Felsenstein, J. (1989). PHYLIP - Phylogeny inference package (version 3.2). Cladistics 5, 164-166.

Groth, I., Schumann, P., Rainey, F. A., Martin, K., Schuetze, B. \& Augsten, K. (1997). Demetria terragena gen. nov., sp. nov., a new genus of actinomycetes isolated from compost soil. Int $J$ Syst Bacteriol 47, 1129-1133.

Mesbah, M., Premachandran, U. \& Whitman, W. B. (1989). Precise measurement of the $\mathrm{G}+\mathrm{C}$ content of deoxyribonucleic acid by high-performance liquid chromatography. Int J Syst Bacteriol 39, 159-167.

Minnikin, D. E., Collins, M. D. \& Goodfellow, M. (1979). Fatty acid and polar lipid composition in the classification of Cellulomonas, Oerskovia and related taxa. J Appl Bacteriol 47, 87-95. 
Thompson, J. D., Higgins, D. G. \& Gibson, T. J. (1994). CLUSTAL W: improving the sensitivity of progressive multiple sequence alignment through sequence weighting, position-specific gap penalties and weight matrix choice. Nucleic Acids Res 22, 4673-4680.

Ventosa, A., Marquez, M. C., Ruiz-Berraquero, F. \& Kocur, M. (1990). Salinicoccus roseus gen. nov., sp. nov., a new moderately halophilic gram-positive coccus. Syst Appl Microbiol 13, 29-33.
Ventosa, A., Marquez, M. C., Weiss, N. \& Tindall, B. J. (1992). Transfer of Marinococcus hispanicus to the genus Salinicoccus as Salinicoccus hispanicus comb. nov. Syst Appl Microbiol 15, 530-534.

Yoon, J.-H., Lee, K.-C., Weiss, N., Kang, K. H. \& Park, Y.-H. (2003). Jeotgalicoccus halotolerans gen. nov., sp. nov. and Jeotgalicoccus psychrophilus sp. nov., isolated from the traditional Korean fermented seafood jeotgal. Int J Syst Evol Microbiol 53, 595-602. 